\title{
Effects of an anti-androgen in the laying hen (Gallus domesticus)
}

\author{
M. R. Luck \\ Department of Physiology, University of Southampton, Southampton SO9 5NH, U.K.
}

\begin{abstract}
Summary. The daily injection of the anti-androgen, cyproterone acetate, into regularly laying hens failed to prevent ovulation immediately. The delayed response suggested that testosterone is not part of the ovarian positive feedback stimulus resulting from the presence of an ovulable follicle and leading to ovulation. Ovarian changes in treated birds, and their unimpaired response to LH-RH, suggested that the drug might be acting by altering ovarian steroid metabolism.
\end{abstract}

\section{Introduction}

According to current theory, based on that of Fraps (1961), the release of LH that induces ovulation in the hen is brought about by a positive feedback stimulus from the ovary. This hormonal stimulus is produced by, and indicates the presence of, a mature, ovulable follicle within the ovary. Attempts to establish the nature of this feedback stimulus have shown that several steroids are able to release $\mathrm{LH}$ and cause ovulation when injected into hens. Testosterone and progesterone have been considered to be the most likely steroids involved because they are effective exogenously (Wilson \& Sharp, 1975, 1976; Etches \& Cunningham, 1976; Croze \& Etches, 1980), and also show patterns of endogenous release which would be consistent with such a role (Furr, Bonney, England \& Cunningham, 1973; Shodono, Nakamura, Tanabe \& Wakabayashi, 1975; Etches \& Cunningham, 1977). Etches \& Cunningham (1977) found that an increase in plasma LH concentration was always preceded by an increase in testosterone concentration. In a more detailed study of the patterns of testosterone, progesterone and $\mathrm{LH}$ in the blood, Williams \& Sharp (1978) observed that the small increase in LH output which followed the onset of the dark period was accompanied by a small increase in the steroid concentrations. However, both steroids showed a much larger increase in concentration in association with the preovulatory LH surge. Williams \& Sharp (1978) considered the change in progesterone output to be the more important, although subsequent in-vitro investigations (Davidson, Gilbert \& Wells, 1979; Wells, Gilbert \& Culbert, 1980) demonstrated that the ability to secrete progesterone is not confined to mature follicles and that the progesterone response of the granulosa cell layer to LH does not increase with increasing follicular size. There is no comparable information on the ability of the maturing follicles to secrete androgens. However, large and possibly pharmacological doses of exogenous androgen need to be injected to induce ovulation (Croze \& Etches, 1980). The in-vitro incubation of pituitary cells (Luck \& Scanes, 1980) showed that testosterone, at a concentration about 10 times greater than that which occurs before ovulation in the normal cycle, could stimulate LH release directly and that the anti-androgen cyproterone acetate could block this effect. The importance of androgen in the ovarian feedback mechanism was investigated in the present experiments using cyproterone acetate in vivo. 


\section{Materials and Methods}

Twelve regularly laying hens (Light Sussex $\times$ Rhode Island Red), approximately 25 weeks of age, were housed individually with unrestricted access to layers' meal and water and given a minimum of $14 \mathrm{~h}$ light in $24 \mathrm{~h}$. Twice daily inspection of the birds provided records of egg lay and enabled subjective visual assessment of the condition of comb, wattles and plumage.

Cyproterone acetate (17 $\alpha$-acetoxy-6-chloro-1 $\alpha, 2 \alpha$-methylenepregna-4,6-diene-3,20-dione; Schering Chemicals), dissolved in a slightly acidified equivolumetric mixture of propylene glycol and absolute alcohol was administered subcutaneously (nape of neck) to half the hens at a rate of $25 \mathrm{mg}$ bird $^{-1} \mathrm{day}^{-1}$. The remaining control hens received the vehicle alone. Blood samples, obtained by wing vein puncture in the mid-afternoon period $(15.00-16.00 \mathrm{~h})$, were taken just before the first injections of cyproterone acetate or vehicle and at intervals over the course of the experiment. After injections for 20 days, the pituitary responsiveness of each hen was tested by the intravenous injection of $25 \mu \mathrm{g}$ of LH-releasing hormone ( $\mathrm{LH}-\mathrm{RH})$ in saline $(9 \mathrm{~g} \mathrm{NaCl} / \mathrm{l})$. Blood samples were taken at $0,5,10$ and $60 \mathrm{~min}$ after the injection. All blood samples were stored deep frozen as heparinized plasma until assayed for $\mathrm{LH}$ by the specific radioimmunoassay of Follett, Scanes \& Cunningham (1972). After a total of 25 days of injections, the hens were killed by neck fracture and a post-mortem examination of the internal organs was carried out.

\section{Results}

Before the start of injections, both groups of hens had an average rate of lay of 4-5 eggs hen ${ }^{-1}$ week $^{-1}$. The control hens maintained this rate of production throughout the experiment. Four of the 6 treated hens laid within $36 \mathrm{~h}$ of the first injection of cyproterone acetate and all produced at least 4 eggs over the first 6 days of treatment; 2 hens laid on Day 7 and one other laid on Day 8, this being the final egg produced by hens in the treated group. No soft-shelled eggs were laid and, although an accurate egg recording system was not available, there appeared to be no irregularities in the times of lay as compared with those before the start of injections. By Day 5 the combs and wattles of the cyproterone acetate-treated birds were noticeably reduced in turgor and brightness when compared with those of the controls. Differences in comb size and a marked loss of plumage condition were noted from about Day 10.

Table 1. Concentration of $\mathrm{LH}\left(\mathrm{ng} \mathrm{ml}^{-1}\right)$ in plasma of cyproterone acetate-treated and control hens

\begin{tabular}{|c|c|c|c|c|}
\hline \multirow[b]{2}{*}{ Treatment } & \multirow{2}{*}{$\begin{array}{c}\text { No. of } \\
\text { hens }\end{array}$} & \multicolumn{3}{|c|}{ Time of treatment } \\
\hline & & Day 0 & Day 14 & Day 20 \\
\hline Cyproterone acetate & 6 & $1.42 \pm 0.24$ & $0.80 \pm 0.14^{*}$ & $0.83 \pm 0.09^{* *}$ \\
\hline Control & 6 & $1.17 \pm 0.16$ & $1.29 \pm 0.14$ & $1.35 \pm 0.16$ \\
\hline
\end{tabular}

By Day 14 there was a fall of some $44 \%$ in the plasma $\mathrm{LH}$ concentrations of the treated hens, with a similar value being recorded on Day 20 (Table 1). Despite the lower basal concentration in the treated hens, the treated and control groups showed similar $\mathrm{LH}$ response curves to the injection of LH-RH (Text-fig. 1). The mean LH concentration had doubled in the treated group by $10 \mathrm{~min}$, the two groups showing similar absolute increases in LH output over this time. 


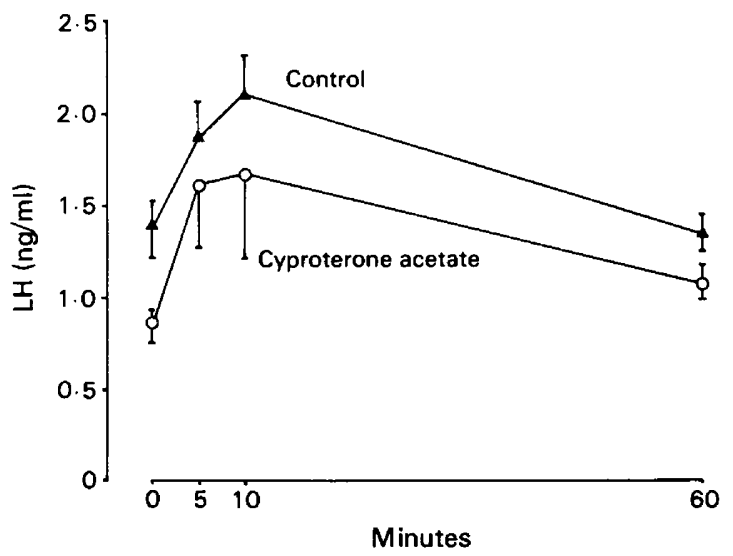

Text-fig. 1. Effect of LH-RH ( $25 \mu \mathrm{g}$, i.v. at $0 \mathrm{~min})$ on mean \pm s.e.m. plasma concentrations of LH in 6 cyproterone acetate-treated and 6 control hens.

After 25 days there were significant reductions in the weights of comb, ovary and oviduct in the treated hens as compared with those of the controls (Table 2). Oviducts were typically thin walled and narrow and lacked clear macroscopic differentiation. Ovaries contained no follicles over $4 \mathrm{~mm}$ diameter and no discernible follicular hierarchy; there were many atretic follicles. The large abdominal and subcutaneous fat deposits seen in control hens were absent or greatly reduced in the treated birds. Similarly, the treated birds showed little evidence of active yolk-protein synthesis or storage in the liver, although liver weights were not significantly lower than in the controls.

Table 2. Body and organ weights post mortem in cyproterone acetate-treated ( 25 days) and control hens

\begin{tabular}{lcc}
\hline \multicolumn{1}{c}{ Weight } & $\begin{array}{c}\text { Cyproterone acetate- } \\
\text { treated hens } \\
(\mathrm{N}=6)\end{array}$ & $\begin{array}{c}\text { Control hens } \\
(\mathrm{N}=6)\end{array}$ \\
\hline Body $(\mathrm{kg})$ & $1.72 \pm 0.12$ & $2.03 \pm 0.12$ \\
Comb $(\mathrm{g})$ & $2.60 \pm 0.39^{*}$ & $6.00 \pm 1.32$ \\
Liver $(\mathrm{g})$ & $35.5 \pm 4.3$ & $46.4 \pm 3.8$ \\
Oviduct $(\mathrm{g})$ & $14.3 \pm 1.6^{* *}$ & $48.5 \pm 5.8$ \\
Ovary $(\mathrm{g})$ & $3.6 \pm 0.3^{* *}$ & $37.7 \pm 7.2$ \\
\hline \multicolumn{3}{c}{ Values are mean \pm s.e.m. } \\
\multicolumn{2}{c}{ Significantly different from control value: ${ }^{*} P<0.05 ;$} \\
${ }^{* *} P<0.001$ (Student's $t$ test).
\end{tabular}

\section{Discussion}

The only previous report of the action of cyproterone acetate in the chicken is that of Wollman \& Hamilton (1968) who found that the drug could block directly the androgen-sensitive comb growth of the chick. With no direct information on its mechanism of action, it must therefore be assumed that cyproterone acetate acts by blocking receptor sites on androgen target organs, as described for mammals by Neumann \& Schenck (1976).

If the avian pituitary gland is such an organ and if androgen feedback is important in the daily initiation of ovulation in the manner suggested by Etches \& Cunningham (1977) and Williams \& Sharp (1978), then a swift response to the drug would be expected. In the absence of more information on the dose effectiveness and metabolic activity of cyproterone acetate in the 
hen, the possibility that the drug took several days to build up an adequate receptor block cannot be excluded. However, the loss of lay took as long to become established as did the visible changes in the comb, wattles and plumage and the temporal pattern of lay, as far as could be determined, was not greatly distorted. These observations and the post-mortem results suggest that the ovulatory system was affected by a gradual influence of the drug on the follicular responsiveness of the ovary, rather than by an interruption in the cyclic control of the pituitary-hypothalamic complex. It therefore appears that daily androgen feedback is not required to maintain daily ovulation in the hen, suggesting that previous reports of the LH-inducing properties of androgens, in vivo and in vitro, represent pharmacological effects as proposed by Croze \& Etches (1980), possibly through the conversion of the hormone to an active metabolite such as 4-androstene-3,17-dione (Davies, Massa \& James, 1980; Croze \& Etches, 1980).

The nature of the anti-follicular action of cyproterone acetate is not clear. Although tonic LH secretion was considerably reduced in the treated birds, their response to $\mathrm{LH}-\mathrm{RH}$ demonstrated that the capacity of the pituitary to secrete a substantial quantity of LH was not impaired by the drug. It is therefore possible that the drug affected only that part of the gonadotrophin secretion mechanism which is responsible for ovarian maintenance. If this was a direct pituitary-hypothalmic action, it suggests that androgens are normally involved in a positive-feedback loop concerned with follicular maturation.

However, cyproterone acetate could have affected the ovary itself. Whilst ovarian androgens have been implicated as part of the steroidal requirements of the oviduct (Gilbert, 1971), it is unlikely that the ovary is an androgen target organ (although the possibility of dependence on adrenal androgen cannot be excluded). A more attractive explanation is that the drug had an adverse effect on ovarian steroid metabolism. This would not only reduce oviduct maintenance and yolk protein synthesis in the liver but would also interrupt the production and maintenance of follicles by a steroid-gonadotrophin loop. In keeping with this, cyproterone acetate has been found to reduce $3 \beta$-hydroxysteroid dehydrogenase activity in amphibian ovaries (Hsu, Hsu \& Liang, 1979) as well as in human placental microsomes (Schwarzel, Kruggel \& Brodie, 1973). On the other hand, the continuation of ovulation for a week after the start of injections shows that ovarian progesterone production was not immediately switched off, if indeed a rise in the plasma progesterone concentration is necessary for the initiation of the preovulatory LH surge. There is good evidence that the ovulation mechanism itself depends upon the presence of progesterone at the point of follicular rupture (Tojo \& Huston, 1981) although cyproterone acetate can have progestational activity (Neumann \& Schenck, 1976) and may have provided this.

I am grateful to Dr P. Sharp, Poultry Research Centre, Edinburgh, for performing the LH assays, to Dr K. Clemens, Schering Chemicals, for the gift of cyproterone acetate, and to the National Pituitary Agency, NIAMDD, for the gift of LH-RH.

\section{References}

Croze, F. \& Etches, R.J. (1980) The physiological significance of androgen-induced ovulation in the hen. J. Endocr. 84, 163-171.

Davidson, M.F., Gilbert, A.B. \& Wells, J.W. (1979) Activity of ovarian $\Delta^{5}-3 \beta$-hydroxysteroid dehydrogenase in the domestic fowl with respect to age. $J$. Reprod. Fert. 57, 61-64.

Davies, D.T., Massa, R. \& James, R. (1980) Role of testosterone and its metabolites in regulating gonadotrophin secretion in the Japanese quail. J. Endocr. 84, 211-222.
Etches, R.J. \& Cunningham, F.J. (1976) The interrelationship between progesterone and luteinizing hormone during the ovulation cycle of the hen (Gallus domesticus). J. Endocr. 71, 51-58.

Etches, R.J. \& Cunningham, F.J. (1977) The plasma concentrations of testosterone and $\mathrm{LH}$ during the ovulation cycle of the hen (Gallus domesticus). Acta endocr., Copenh. 84, 357-366.

Follett, B.K., Scanes, C.G. \& Cunningham, F.J. (1972) A radioimmunoassay for avian luteinizing hormone. J. Endocr. 52, 359-378. 
Fraps, R.M. (1961) Ovulation in the domestic fowl. In Control of Ovulation, Vol. 1, pp. 133-162. Ed. C. A. Villee. Pergamon, New York.

Furr, B.J.A., Bonney, R.C., England, R.J. \& Cunningham, F.J. (1973) Luteinizing hormone and progesterone in peripheral blood during the ovulatory cycle of the hen (Gallus domesticus). J. Endocr. 57, 159-169.

Gilbert, A.B. (1971) Egg albumen and its formation. In Physiology and Biochemistry of the Domestic Fowl, vol. 3, Ch. 54, pp. 1237-1248. Eds D. J. Bell \& B. M. Freeman. Academic Press, London.

Hsu, C.Y., Hsu, L.H. \& Liang, H.M. (1979) The effect of cyproterone acetate on the activity of $\Delta^{5}-3 \beta$ hydroxysteroid dehydrogenase in tadpole sex transformation. Gen. \& comp. Endocr. 33, 404-410.

Luck, M.R. \& Scanes, C.G. (1980) Ionic and endocrine factors influencing the secretion of luteinizing hormone by chicken anterior pituitary cells in vitro. Gen. \& comp. Endocr. 41, 260-265.

Neumann, F. \& Schenck, B. (1976) New anti-androgens and their mode of action. J. Reprod. Fert., Suppl. 24, 129-145.

Schwarzel, W.C., Kruggel, W.G. \& Brodie, H.J. (1973) Studies on the mechanism of estrogen biosynthesis. VIII. The development of inhibitors of the enzyme system in human placenta. Endocrinology 92, 866880.

Shodono, M., Nakamura, T., Tanabe, Y. \&
Wakabayashi, K. (1975) Simultaneous determination of oestradiol-17 $\beta$, progesterone and luteinizing hormone in the plasma during the ovulatory cycle of the hen. Acta endocr., Copenh. 78, $565-573$.

Tojo, H. \& Huston, T.M. (1981) Effects of steroid blockers on $\mathrm{LH}$-induced ovulation in the domestic fowl, Gallus domesticus. J. Reprod. Fert. 61, 381386.

Wells, J.W., Gilbert, A.B. \& Culbert, J. (1980) Effect of luteinizing hormone on progesterone secretion in vitro by the granulosa cells of the domestic fowl (Gallus domesticus). J. Endocr. 84, 249-254.

Williams, J.B. \& Sharp, P.J. (1978) Control of the pre-ovulatory surge of luteinizing hormone in the hen (Gallus domesticus): the role of progesterone and androgens. J. Endocr. 77, 57-65.

Wilson, S.C. \& Sharp, P.J. (1975) Changes in plasma concentrations of luteinizing hormone after injection of progesterone at various times during the ovulatory cycle of the domestic hen (Gallus domesticus). $J$. Endocr. 67, 59-70.

Wilson, S.C. \& Sharp, P.J. (1976) Effects of androgens, oestrogens and deoxycorticosterone acetate on plasma concentrations of luteinizing hormone in laying hens. J. Endocr. 69, 93-102.

Wollman, A.L. \& Hamilton, J.B. (1968) Direct action upon avian target organs by the antiandrogen cyproterone acetate. Anat. Rec. 161, 99-104.

Received 29 April 1981 